\begin{tabular}{lllllllllllllllllllllllllllllllll}
\hline$R$ & $E$ & $V$ & I & S & T & A & D & E & E & S & T & U & D & I & O & S & I & N & T & E & R & N & A & C & I & O & N & A & L & E & S
\end{tabular}

\title{
La doctrina Bush y los demonios de la inseguridad
}

\author{
José Rodríguez Elizondo
}

Los medios muestran hoy al presidente George W. Bush recorriendo las bases militares de los Estados Unidos en ultramar y promoviendo ante otros líderes del mundo una visión musculada del orden que debiera imperar en el planeta. No fue ésa su imagen durante la campaña electoral. Contrastada con la de su oponente demócrata Al Gore-académico de diálogo fluido con los otros poderosos de la tierra y con experiencia en labores de superpotencia autocontenida-, la del candidato republicano lucía simpática y civil, pero doméstica.

Su cambio de imagen surgió como consecuencia del atentado terrorista del 11 de septiembre de 2001 (11-S) y no fue simplemente cosmético. Vino para ilustrar un viraje dramático en la política exterior de los Estados Unidos. Uno que, por añadidura, está afectando el sistema internacional, con un prospecto de "guerras preventivas", decididas de manera unilateral y al margen del sistema de seguridad colectiva.

Trataremos de dar cuenta de esta materia, a partir de una hipótesis de situación inicial con "fuga hacia adelante", la teoría tras la guerra antiterrorista, su dinámica adictiva, la crisis eventual de la ONU, la crítica de los intelectuales, la Doctrina Bush, un balance de seguridad interna en los Estados Unidos y una proyección sobre el futuro de Occidente, con acompañamiento de Huntington y Fukuyama.

HIPÓTESIS DE INICIO CON FUGA

o primero que el observador supone es que un viraje político tan dramático como el que está operando desde la Casa Blanca implica un complejo y previo proceso de análisis por parte del presidente. Una reflexión histó- rica, estratégica e internacionalmente ilustrada, que le permita prever no sólo los desarrollos domésticos, sino los efectos a nivel mundial.

Sin embargo, tal proceso no siempre se ha dado en los Estados Unidos. Sea porque la realidad no se preocupa de los espacios para la reflexión o porque el lí- 
der no suele ser elegido por sus dotes de analista, las decisiones dramáticas pueden depender de factores más aleatorios. Por ejemplo, de la reacción emocional ante la acción de un enemigo, de la capacidad de influencia de los asesores más cercanos o de ambos factores a la vez.

Así, la decisión para que los Estados Unidos intervinieran en la Segunda Guerra Mundial fue tomada por un Franklin D. Roosevelt universitario, cosmopolita y altamente sofisticado, pero el momentum que le brindó la realidad fue mínimo. El intempestivo ataque japonés en Pearl Harbour, de diciembre de 1941, impuso una acción sobre la marcha. Más tarde, la dura decisión de usar el arma atómica contra Japón fue adoptada, tras un tiempo razonable de reflexión, por el antitético sucesor de Roosevelt. Esto es, por Harry Truman, un dirigente surgido de la clase media rural del Medio Oeste, carente de educación universitaria y, al decir de Henry Kissinger, "producto de la maquinaria política de Kansas City" 1.

Dado que la Historia norteamericana hoy asigna a Roosevelt y a Truman una excelente posición, lo señalado no implica demasiado en términos de "buenos" y "malos" presidentes. Lo que sí permite -y no es poca cosa- es discernir respecto de las posibilidades del entorno presidencial en contextos de alta tensión, a partir de una hipótesis de relación inversa: a menor espacio de reflexión o a menor vocación presidencial para "complejizar" (en el sentido que dan los intelectuales a esta pala- bra), mayor posibilidad de influencia de su entorno.

Desde esa perspectiva, puede decirse que sólo en la apariencia Roosevelt no tuvo tiempo para decidir. De hecho, su elaboración intelectual ya se había producido y su disposición existía in pectore. Pero Truman, que sí tuvo el tiempo necesario para decidir lo suyo, debió suplir sus supuestas carencias con la asesoría de consejeros civiles y militares. Esto, en el entendido de que ese tipo de asesoría suele ejercerse no sólo mediante "memos" más o menos articulados y registrables. En contextos de apremio histórico, también se ejerce mediante el simple estímulo a las intuiciones del asesorado.

Aplicando lo señalado al actual viraje estratégico norteamericano, podría decirse que la decisión de Bush pareció más impregnada de componentes emocionales genuinos que la de Roosevelt. Esta suposición se funda en que -al margen de la información acumulada y no comunicada por los servicios secretos norteamericanos- el ataque terrorista del 11-S fue menos previsible que el de Pearl Harbour. Bush, por tanto, no podía tener una opción ya procesada o in pectore.

\section{El viraje de Bush fue propio de un presidente poco expuesto a las complejidades de la política exterior.}

Por eso, para muchos analistas su viraje tuvo un sesgo reactivo simple, propio

\footnotetext{
${ }^{1}$ Henry Kissinger, La Diplomacia, México, Fondo de Cultura Económica, 1994, pág. 410
} 
de un Presidente con poca exposición a las complejidades de la política exterior y dependiente, en alto grado, de la influencia de sus "hombres y mujeres de acción". Es decir, de ese colectivo adjunto al poder presidencial, cuyos rostros oficiales de primera línea corresponden al vicepresidente Dick Cheney, al secretario de Defensa Donald Rumsfeld, al Fiscal General John Ashcroft y a la asesora de Seguridad Nacional, Condoleezza Rice.

Por otra parte y a diferencia de Truman, Bush no llegó para seguir la línea trazada por un estadista respetado, como Roosevelt, sino para alterar la línea implantada por un estadista polémico, como Bill Clinton. Sólo que, al intentarlo, comenzó a salir a flote su semejanza curricular con el líder de Kansas. Esa que lo muestra llegando a la Presidencia desde fuera de la elite cosmopolita. En la especie, desde la empresa privada petrolera, un Master en Escuela de Negocios, el metodismo cristiano y la gobernación de un Estado tan peculiar como Texas.

(Vale la pena advertir que ese talante doméstico de Bush ya se hizo aparente durante la campaña electoral. Sus "creativos" trataron, entonces, de mostrarlo con un récord militar medianamente consistente, como aviador de la Guardia de su estado. Quizás pensaron que así compensarían la falta de un currículo con mención de Vietnam. Como se sabe, el diario Globe descubrió serios y no desmentidos errores en dicha información)

Desde tal base, el entonces candidato Bush no pudo disimular que no entendía bien la profundidad del cambio global tras el fin de la Guerra Fría pues, a escala de superpotencia, su mundo era parroquial. Su mayor experiencia en política exterior provenía de la mesa familiar, compartida con su padre ex director de la CIA, ex vicepresidente y ex presidente. Tal vez por eso, sus discursos de campaña eran contenidos. En ellos solía invocar una imagen nacional de fortaleza con humildad, apta para revertir la de "nación arrogante", que concitaba más temor que respeto. Luego, la necesidad de asumir la presidencia por decisión judicial, tras una especie de empate técnico con $\mathrm{Al}$ Gore, hizo presumir que rehuiría los virajes importantes o las mutaciones dramáticas. Parecía condenado a vegetar en el bajo perfil internacional, dejando que la pos guerra fría encontrara su propia vía hacia un nuevo orden.

\section{La imagen de "nación arrogante" inspiraba más temor que respeto.}

Sin embargo, los acontecimientos del 11-S cambiaron todos los cuadros prediseñados y levantaron los límites impuestos o supuestos. Su carácter espectacular, abrió a Bush -y a sus asesores- la posibilidad de innovar de manera correlativa en materias de política exterior. Y, visto que ni los más prolijos análisis previos contenían una mínima aproximación a lo sucedido, pudo permitirse hasta prescindir de la jurisprudencia política acumulada entre Pearl Harbour y la Guerra del Golfo.

Estuvo, además, el factor personalísimo. Bush, en la confusión del momento, se dejó esconder por los agentes de seguridad, 
mantuvo al país por 24 horas sin liderazgo visible y luego apareció conmovido, pero demasiado quiet man, ante cámaras y micrófonos. El ex gobernante español Felipe González diría, comentando esa comparecencia, que "no hay nada más inquietante que ver al presidente de Estados Unidos, después de que no ha podido ir durante todo el día a la Casa Blanca, salir en televisión y decirle al pueblo americano que puede estar tranquilo".2.

\section{La espectacularidad de los} acontecimientos del 11-S permitió al presidente innovar en materias de política exterior.

Pasado ese trago amargo, Bush plantearía al mundo el dilema de hierro de estar a favor o en contra de una política antiterrorista global, que iría diseñando sobre la marcha, que comprendería hasta las guerras preventivas y que hoy se está convirtiendo en "doctrina". En cuanto a su propia imagen, también entendió -tal vez tras visionar videos en privado- que la desconcertante vulnerabilidad norteamericana lo obligaba a cambiar la camisa texana del conservador rural, enfundarse la casaca de cuero marrón de los aviadores norteamericanos y aterrizar en la pista pura y dura de los guerreros.

El gran cambio se oficializó el día 7 del mes siguiente al atentado, cuando dio la salida a sus tropas hacia Afganistán. En su discurso a la nación asumió el ran- go militar máximo, mostrando la cruz y la espada: "Un comandante en jefe envía a los hijos e hijas de América a la batalla en un país extranjero, pero con el mayor de los cuidados y después de muchas oraciones".

Así comenzó lo que hoy muchos consideran una "fuga hacia adelante".

\section{LA ARREMETIDA}

Para dar contenido a su nueva imagen, mezcla de caballero cruzado y llanero solitario, Bush superó la tentación del aislacionismo clásico (ese "rol más reducido" que postulaban algunos politólogos), embarcándose en una estrategia de intervencionismo unilateral, con dos objetivos básicos: primero, perseguir al terrorismo islámico en cualquier parte, para garantizar la seguridad nacional. Segundo, consolidar la hegemonía global de los Estados Unidos, incluso mediante guerras preventivas.

Para el cumplimiento de dichos objetivos, soslayaría los costos sociales y políticos tradicionales -ayuda al desarrollo y busca de consensos- sustituyendo la negociación por la simple notificación de intenciones, aunque con ello afectara compromisos previos.

Consecuente con ello, retiró a su país de los protocolos ambientalistas de Kyoto, rechazó el Tribunal Penal Internacional, amenazó con sanciones a quienes juzga-

\footnotetext{
${ }^{2}$ Felipe González y Juan Luis Cebrián, El futuro no es lo que era, Madrid, Aguilar, 2001, $5^{\text {a }}$ ed., pág. 243
} 
ran ante éste a sus agentes en el exterior, desahució el tratado de defensa antimisiles con Rusia, exhumó el sistema de defensa espacial de Ronald Reagan ("guerra de las galaxias") y aumentó en 40 mil millones de dólares el presupuesto militar.

En esta línea incluso rectificó su inicial política de laissez faire en el Medio Oriente, según la cual había que dejar que israelíes y palestinos se las arreglaran solos. También se arriesgó a mostrar desaprensión respecto de las limitaciones que implica la doctrina occidental sobre derechos humanos. Amnesty International ya le reprochó haber negado la condición de prisioneros de guerra a los soldados del régimen talibán. También se le ha criticado la detención de personas, no ciudadanos de los Estados Unidos, por tiempo indefinido y sin presentarlos a la justicia; el espionaje electrónico de conversaciones entre los procesados y sus abogados, y la acusación secreta, ante las cortes de inmigración, en contra de extranjeros.

Más llamativo aún, a fines de febrero del 2002, el presidente apareció indirectamente vinculado a una "Oficina de Influencia Estratégica”, encargada, según The New York Times, de "proveer de noticias, incluso falsas, a los medios de comunicación extranjeros".

Dicen los que saben que la irlandesa Mary Robinson, Alta Comisionada de las Naciones Unidas para los Derechos Humanos, adelantó su retiro del cargo por la resistencia a su gestión manifestada desde instancias del gobierno norteamericano.

\section{LA FUERZA COMO RAZÓN}

Tras esa arremetida inicial se disciernen tres circunstancias funcionalizadas: la disposición psicológica de la nación, tras el 11-S, para infligir un castigo inmediato a los terroristas, la liberación de la fuerza de los Estados Unidos tras su triunfo en la Guerra Fría y la experiencia de las intervenciones de baja intensidad de Bill Clinton.

\section{Las largas décadas de Guerra Fría rigidizaron la política exterior de los Estados Unidos.}

Respecto de la primera, la Historia parecía enseñar a Bush que cualquier movimiento mayor, en los departamentos de Defensa o de Estado, precisaba un catalizante dramático o un trabajo de mediano plazo. Sólo el "día de la traición" (Pearl Harbour) permitió a Roosevelt comprometerse en la Segunda Guerra Mundial y Lyndon Johnson debió fraguar el incidente del Golfo de Tonkin, para que el Congreso aprobara su escalada en Vietnam. Por otra parte, tuvieron que llegar los acuciosos nixinger para efectuar un prolijo acercamiento a China, funcional para jaquear a la Unión Soviética y comenzar a socavar las murallas del socialismo real.

La segunda circunstancia le decía que las largas décadas de Guerra Fría rigidizaron la política exterior de los Estados Unidos. El juego suma cero, con el carácter total de sus eventuales ganancias o pérdidas, obligaba a difíciles consen- 
sos internos y externos, que terminaban convirtiéndose en políticas de Estado. En 1962, John F. Kennedy no pudo invadir Cuba ni siquiera esgrimiendo una amenaza nuclear cercana. A contrario sensu, el fin de la Guerra Fría permitió a Bush padre, en 1991, ejecutar la Guerra del Golfo a partir de una amenaza radicada en la Península Arábiga. El momento de inflexión se produjo cuando Ronald Reagan tomó la decisión política de poner fin al empate estratégico, asumiendo el riesgo de subir el umbral del equilibrio armamentista.

\section{Los virajes bruscos no deben subordinarse necesariamente a elaboraciones doctrinarias.}

En cuanto a la experiencia de su predecesor, ¿cómo no recordar que incluso el firme y sostenido esfuerzo político de Clinton en el Medio Oriente terminó, el año 2000, como un paradigma del fracaso? ¿O que, en vez de nuevas estrategias militares, Clinton empezó planteando una política de tolerancia para los gays de las Fuerzas Armadas?

Los hechos le decían que, a sólo 38 días de instalado, ese presidente debió asumir el primer atentado de $\mathrm{Al}$ Qaeda contra una de las Torres Gemelas, con seis muertos y miles de heridos. Luego vinieron atentados y secuestros, con muerte de diplomáticos y militares norteamericanos, en Turquía, Pakistán y Arabia Saudita. Hubo ataques espectaculares a las embajadas de su país en Líbano, Kenya y Tanzania, y un atentado contra el destruc- tor Cole, en Yemen, con centenares de víctimas compatriotas. También estuvo el atentado fallido, pero con impacto íntimo: fue en abril de 1993, cuando Bush padre visitaba Kuwait y se puso en la mira de agentes iraquíes.

Para Bush hijo aquello anunciaba una indisciplina perisferica, inducida por los consensos del multilateralismo y la autolimitación de las conductas "políticamente correctas". Sin duda, él debió estar entre quienes dijeron que los misiles Cruise contra campamentos de Al Qaeda, en Sudán y Afganistán, 1998, fueron maniobras diversionistas de Clinton, para zafarse de la trampa Lewinsky.

James Woolsey, ex director de la CIA, entrevistado por la National Review, pareció darle la razón cuando definió la política de Clinton contra el terrorismo como la necesidad simple de demostrar preocupación: "Lanzar algunos misiles en el desierto, darles un golpecito en la cabeza, detener a algunas personas, pero, sobre todo, lanzar lejos el balón”.

\section{LA RAZÓN COMO FUERZA}

Las tres circunstancias mencionadas fortalecieron las posiciones del entorno presidencial "de acción". Esto es, de quienes, invirtiendo el aforismo marxiano que privilegia las armas de la crítica sobre la crítica de las armas, creen que los virajes bruscos no deben subordinarse, necesariamente, a elaboraciones doctrinarias.

Con todo, ya existía una fundamentación teórica idónea, aunque difusa, para consumo interno y externo. En 
efecto, en el ambiente polítológico norteamericano estaban las piezas necesarias para dar cobertura ideológica al viraje de Bush. Eran las ideas personalizadas en autores como Francis Fukuyama, Henry Kissinger, Zbigniew Brzezinski y Lester Thurow, teóricos de renombre en los cuales se mezclan la pulsión utópica, la realpolitik, el ideologismo de mercado y las convicciones geopolíticas.

Así, en la nueva estrategia de la Casa Blanca pueden detectarse cuatro tesis básicas:

Primera: la del fin de la Historia, en el sentido de que ya no hay alternativas sistémicas para las sociedades paradigmáticas de Occidente, con sus regímenes democráticos y economías de mercado. De esta tesis se desprende, por una parte, que ya no es necesario ceder cuotas de soberanía para generar consensos frente al enemigo. Por otra parte, es una especie de exequatur para desligarse de la vieja tesis onusiana que vincula la seguridad de los países ricos con el desarrollo de los países pobres. Si el sistema no se sostiene solo en estos países, quiere decir que no son viables.

Segunda: la tesis de que en un mundo política y económicamente multipolar, la superioridad militar de los Estados Unidos es su única ventaja comparativa. Esto implica que, en lugar de relajar sus fuerzas, la superpotencia debe mantenerlas en tensión, renovarlas y potenciarlas. La idea es que, en definitiva, los Estados Unidos están llamados a convertirse en proveedor principal de servicios bélicos a los demás países de su civilización, para mantener el orden planetario.

Tercera: la tesis de que si el sistema internacional, basado en el Estado-nación, es desafiado por amenazas transnacionales, éstas pueden ser combatidas en los territorios soberanos de otras naciones. La Guerra Fría lo impidió sólo porque la represalia ponía en peligro la estabilidad global del sistema, basado como estaba en zonas de influencia de dos superpotencias.

\section{Las amenazas transnacionales que afectan al sistema internacional podrían combatirse en los territorios soberanos de otros países.}

Cuarta: la tesis de que la pasividad ante desórdenes periféricos sólo puede justificarse en las situaciones inciertas. Es decir, en aquellos conflictos en "zonas grises", donde los intereses de los Estados Unidos están divididos. Cabe advertir que cuando Bush desarboló la política de honest broker de Clinton en el Medio Oriente, antes del 11-S, no lo hizo sobre esta base más pragmática, sino a partir del aislacionismo tradicional. Ahora, dado que el vacío que dejó sirvió como excusa ideológica para Bin Laden -cuando encubrió su atentado con la causa palestinaesta tesis será de aplicación extremadamente restrictiva.

Como los Estados Unidos distan mucho de ser una sociedad sin debate, estas "coartadas ideológicas" tienen contestatarios disidentes y/o antisistémicos, como 
Noam Chomsky y Edward Said. En junio de 2002, ambos encabezaron un manifiesto firmado por una sesentena de artistas e intelectuales, llamando a resistir "la guerra y la represión lanzadas contra el mundo". En el documento se consigna la siguiente pregunta-acusación: “¿Qué clase de mundo tendremos si Estados Unidos dispone de un cheque en blanco para enviar comandos, asesinos o bombas allí donde quiera?".

\section{Sería prudente estimular la occidentalización de América} Latina y estrechar filas
con los socios europeos.

También están los críticos desde el sistema, como el historiador Paul Kennedy, directivo de la Universidad de Yale y sintomático autor de Auge y caída de las grandes potencias. En declaraciones para la prensa, éste contó de los mensajes que le llegaban de todas partes del mundo, dando a entender que la democracia de los Estados Unidos no es tan admirada y valorada como al norteamericano medio le gusta suponer. "La simpatía extranjera ante los horrores del 11 de septiembre fue sincera, pero era una simpatía por la pérdida de unos seres queridos inocentes; (...) ello no implica un amor y apoyo incondicionales al Tío Sam", dijo. Agregó que la autosuficiente política exterior de Bush se reduciría a "ponernos en marcha con un inmenso peso militar para destruir demonios como los talibanes y retirarnos luego a nuestras bases aéreas y campamentos". Terminó evocando los liderazgos de Woodrow Wilson, Franklin D. Roosevelt y John F. Kennedy, quienes "alegraron los corazones extranjeros al rechazar el sentimiento mezquino de $E s$ tados Unidos primero y hablaron de las necesidades de toda la humanidad"3.

En una especie de oposición académica está Samuel Huntington, director del Instituto John M. Olin de la Universidad de Harvard. Desde su interrogativo artículo de 1993, Clash of civilizations?, éste profesor viene planteando que el triunfalismo de Occidente puede inducir una guerra intercivilizacional. En su libro homónimo, pero ya asertivo, de 1997, asevera que "los Estados Unidos no pueden ni dominar el mundo ni escapar de él". De ahí que a Huntington le parezca prudentísimo estimular la occidentalización de América Latina, renunciar a todo extremismo y estrechar filas con los socios europeos. Resume su posición en una advertencia: "Las sociedades que suponen que su historia ha terminado son sociedades cuya historia comienza a declinar".

Interrogado por un periodista español, a menos de un mes del 11-S, Huntington se confirmó a sí mismo, diciendo que los Estados Unidos debían continuar la ampliación de la UE y de la OTAN para incluir Estados occidentales de Europa central, impulsar la occidentalización de América Latina y reconocer que Rusia tiene intereses legítimos en la seguridad de sus fronteras meridionales. Además, rei-

\footnotetext{
${ }^{3}$ Paul Kennedy, El País, 7-3-02.
} 
teró que incluso ese Occidente ampliado y consolidado debía reconocer que "la intervención en los asuntos internos de otras civilizaciones, salvo cuando haya en juego intereses vitales, es la fuente más peligrosa de un posible conflicto global" ${ }^{\text {. }}$.

\section{ACCIÓN CON ADICCIÓN}

Como los hechos militares y/o bélicos reducen las pulsiones opositoras domésticas y elevan el rating del conductor político, la aceptación inicial de Bush de un $55 \%$ subió a un $89 \%$, en los primeros meses tras su réplica al atentado.

Lo malo de ese contexto de medición es que los malos resultados -entre los cuales están los empates- garantizan un descenso rápido, que incluso sobrepasa los indicadores iniciales. Ergo, los altos indicadores deben sostenerse con nuevos hechos de la misma naturaleza.

Es lo que los Estados Unidos y el mundo están experimentando. Visto que, al cumplirse un año del 11-S, su porcentaje de aceptación había bajado hasta un $60 \%$, Bush ahora está en esa trampa que Wright Mills llamaba "percepción militar de la realidad". Es decir, enfrenta la supuesta necesidad de actuar militarmente para mantener alto su rating de líder, aunque existan alternativas menos espectaculares. Como diría un personaje de Lewis Carroll, hoy debe correr incesantemente para permanecer en el mismo sitio.

El presidente está obligado, entonces, a maximizar la importancia de la derrota del régimen talibán, minimizar la importancia de la falta de noticias sobre Osama bin Laden y el mulah Omar, soslayar que los talibanes siguen causando bajas a sus soldados y que ya han atentado contra Hamid Karzai, el presidente afgano instalado. Pero, por sobre todo, debe producir o insinuar planes de contingencia para nuevos teatros de operaciones. Ésa sería la lógica tras su retórica reaganiana sobre la necesidad de terminar con el "eje del mal" formado por Irak, Irán y Corea del Norte.

\section{El presidente de Estados Unidos estaría en la trampa de la "percepción militar de la realidad".}

Corroborando lo señalado, el diario Los Angeles Times del 9 de marzo, ya había citado un documento clasificado del Departamento de Defensa, según el cual el gobierno habría pedido al Pentágono planes de contingencia para el uso de armamento nuclear contra los tres países maléficos, más China, Rusia, Libia y Siria. Al mismo tiempo, solicitaba armas nucleares de pequeño tamaño para su empleo eventual en un conflicto árabeisraelí, un ataque contra Israel por parte de Irak u otro país vecino, una guerra entre China y Taiwán o un ataque de Corea del Norte contra su vecina del Sur.

Esa presión para intervenir explica, además, la presencia de personal militar norteamericano en Kuwait, Filipinas y Georgia, mientras efectivos adicionales

\footnotetext{
${ }^{4}$ Samuel Huntington, El País, 24-10-01.
} 
esperan en la banca, para actuar en Yemen y Somalía.

También explica la pretensión de aumentar en un 27 por ciento el financiamiento de un programa para reforzar las fuerzas armadas en otros países, a semejanza de los viejos Pactos de Ayuda Militar para América Latina. El dinero, el material y los asesores militares estadounidenses irían a Indonesia, Uzbekistán, Nepal, Jordania, Pakistán, Kazajstán y Kirguistán.

\section{LÍMITES DEL UNILATERALISMO}

Difícil es pronosticar dónde tropezará Bush con la piedra de toque. Pero, si bien su popularidad interna actual todavía supera a la de su toma de posesión, la motivación nacional del 11-S está chocando contra realidades menos manejables de lo que suponía.

De arranque, ilustrando la precariedad de las políticas que privilegian la sola fuerza, el terrorismo sigue actuando a nivel global y diversos caudillos afganos vuelven a ejercer su vocación feudal. Al efecto, tratan de consolidar su poder en dominios privados extensibles, postergando la construcción de un verdadero Estado. Asumen que la de Bush fue una guerra sin plan Marshall y que no habrá recursos para lo que los cientistas sociales llaman "proceso de construcción nacional" (nation building).

En cuanto a la extensión iraquí de esa guerra, Bush choca contra los fantasmas históricos de la geopolítica del petróleo. Por sobre la indiscutible peligrosidad de
Saddam Hussein, amigos y enemigos de los Estados Unidos temen que la superpotencia pueda, en virtud de una guerra preventiva complicada, inducir alteraciones cataclísmicas en la economía de ese recurso y/o asumir un control incontrarrestable sobre su gestión.

\section{La motivación nacional del 11-S está chocando con realidades} menos manejables de lo supuesto.

En sus contactos directos con líderes de otras culturas, Bush ya ha recibido muestras claras de desconfianza o escepticismo. Durante su visita de febrero a Corea del Sur, percibió los problemas que planteaba al presidente Kim Dae Jung la inclusión de Corea del Norte en el terceto diabólico. Ello era incompatible con su estrategia de acercamiento y diálogo con el líder norcoreano Kim Jong II. Días después, en China, chocaría con la mezcla de perplejidad y frialdad de Jian Zemin, quien no subestima lo que la nueva estrategia norteamericana significaría para el rol emergente de su país y sus intereses en Taiwan. Cabe advertir que China, potencia nuclear, ha venido incrementando sistemáticamente y en altos porcentajes, su presupuesto militar.

$\mathrm{Su}$ vinculación con el dictador pakistaní, Pervez Musharraf le ha hecho descubrir otras esencias de la complejidad asiática. Obtuvo su colaboración en la campaña afgana contra los talibanes, pero esa amistad le resulta incómoda desde la perspectiva del conflicto entre India y Pakistán. El poder nuclear de ambas 
potencias esboza un escenario apocalíptico para la subregión, expandible al Medio Oriente.

En Israel, precisamente, el Primer Ministro Ariel Sharon le planteó un desafío impensado. Asumiendo los mismos argumentos y desplantes de Bush y gracias al dudoso liderazgo de Arafat, redujo los espacios de su canciller Shimon Peres y siguió privilegiando la fuerza militar en el conflicto con los palestinos. Con ello, puso al gobierno norteamericano en la necesidad de reconsiderar su crítica a la política arbitral de Clinton, para no antagonizar con los países árabes que lo apoyaron en la primera fase de la guerra antiterrorista.

$\mathrm{Ni}$ siquiera el propio hemisferio se ha mostrado dúctil. En Colombia, el presidente Andrés Pastrana abrió otra caja de Pandora, en sus últimos meses de gobierno, al desahuciar las conversaciones con la guerrilla de las FARC, catalogada por Bush entre las organizaciones terroristas. Por ello, antes del mes, éste debió obtener una resolución bipartidista de la Cámara de Representantes, instándolo a expandir la asistencia militar a ese país, para "defender su democracia" contra las guerrillas, los paramilitares y los narcotraficantes. Creó así las condiciones para que el Plan Colombia mute de instrumento antidroga a una especie de alianza bélica, en la zona de seguridad vecinal de los Estados Unidos, mucho antes de lo prudente y deseable.

Casi de inmediato comenzaron a explosionar crisis integrales en Argentina y Venezuela, también amenazantes para la estabilidad democrática, sin que pueda decirse que Ecuador y el Perú hayan salido de sus crisis respectivas. Simultáneamente, las economías de Brasil y Uruguay entraron a un período crítico. Todo esto amenaza la viabilidad del desarrollo democrático de América Latina, uno de los raros éxitos invocados por los Estados Unidos en la región y, en especial por Bush padre, autor de la Iniciativa para las Américas.

\section{La exasperación del cuadro de crisis podría inducir una proliferación de conflictos abiertos.}

La eventual exasperación de este cuadro global podría inducir una proliferación tal de conflictos abiertos, que los muchos Vietnam con que soñaba el Che Guevara parecerían juegos de boy scouts.

\section{CRÍTICA INTERNA Y EXTERNA}

Como el político es un animal de instinto previsor, las críticas domésticas hacia la estrategia de garrote sin zanahoria $\mathrm{y}$ en solitario han ido in crescendo.

Comenzaron con un rezongón comentario del senador demócrata Robert Byrd, presidente del estratégico Comité de Asignaciones (el que autoriza al gobierno norteamericano para recaudar impuestos): "Si esperamos matar a todos los terroristas del mundo, vamos a estar en ello hasta el día del juicio final", dijo, junto con advertir que no deseaba firmar cheques en blanco para operaciones en Georgia. De otra parte, un republicano de 
tanto peso en el Capitolio como el congresista Henry Hyde, presidente del Comité de Relaciones Internacionales, vinculó la aprobación de ayudas a la reconstrucción de Afganistán a una condición dirigida directamente a Bush: lo conminó a dar explicaciones sobre su estrategia para evitar que ese país entre en una nueva espiral hacia el caos y le exigió "un plan efectivo".

\section{Han aumentado las críticas internas a la estrategia del garrote sin zanahoria.}

A fines de mayo de 2002, este tipo de críticas adquirió mayor volumen. El demócrata Tom Lantos, miembro del mismo comité, aseguró al diario The Washington Post que si el Gobierno de Bush no aclara su estrategia, la situación puede deteriorarse "y fracasaremos en la guerra contra el terrorismo en Afganistán".

En septiembre, incluso Henry Kissinger estimó necesario hacer un par de advertencias de peso. Aplicando su vieja tesis sobre la utopía de la seguridad nacional absoluta, escribió que "no puede estar ni en nuestro interés nacional ni en el de otros países, que se desarrollen principios que le den a cada nación el derecho de prevención basado en su definición de amenaza a su seguridad". Agregó, con vista a Europa, que "nuestros aliados no pueden quedar a un lado" y que los Estados Unidos "no deben lanzarse por sí solos, unilateralmente, hasta que no hayan evaluado las consecuencias de actuar como un custodio de los intereses globales"

Los líderes europeos, con la excepción del Primer Ministro británico Tony Blair, no tienen mayor interés en terciar contra el bushiano terceto del mal. Temen ser arrastrados a una guerra contra Irak de imprevisibles efectos económicos y con un potencial del mayor riesgo para la seguridad regional y global. Al filo del primer aniversario del 11-S, el canciller alemán Gerhard Schroeder y el presidente francés Jacques Chirac dieron señales negativas sobre su disposición a dar "cheques en blanco" sobre la materia.

Durante los meses anteriores, el conservador británico Chris Patten, Comisionado de asuntos Exteriores de la Unión Europea, denunció las "tendencias absolutistas" de los Estados Unidos. Los socialistas, incluyendo a Blair, aliado de la primera hora, han manifestado que toda estrategia antiterrorista debe tener un componente solidarista o desarrollista. El ministro de Relaciones Exteriores alemán, Joschka Fisher, se quejó de que estuvieran tratando a los amigos como si fueran satélites del imperio. El entonces primer ministro francés Lionel Jospin apuntó que "el mundo es demasiado complejo para que una sola potencia pretenda resolver los problemas del planeta sólo según sus intereses". Felipe González fue especialmente urticante. En el diario El País escribió que en la nueva política de seguri-

\footnotetext{
${ }^{5}$ Henry Kissinger, "El peligro de estar solos", artículo reproducido por La Tercera, 8-9-02.
} 
dad americana, ni la Unión Europea ni la OTAN tienen un papel relevante. Agregó que "una relación leal con Estados Unidos (...) nos obliga a discutir seriamente, como socios, no como súbditos, lo que haya que hacer para combatir la amenaza del terror".

En un nivel más crudo, la estrategia de Bush parece destinada a convertirse en un buen estímulo para los actores extrasistémicos. En Francia, por ejemplo, contribuyó al sobresalto provocado por los nacional-fascistas y antieuropeístas que llevaron a Jean Marie Le Pen a una sorpresiva segunda vuelta en las elecciones presidenciales. En otros países ha catalizado una vasta amalgama de grupos y organizaciones izquierdistas carentes de representación sistémica. El mejor ejemplo, hasta el momento, ha sido la multitudinaria manifestación berlinesa del 23 de mayo, en contra de la política militar de los Estados Unidos, producida durante la visita de Bush a Alemania.

En su informe bianual 2001-2002, el Instituto Internacional de Estudios Estratégicos de Londres sintetizó y organizó este tipo de críticas, advirtiendo que la solución del problema del terrorismo no supone el uso exclusivo de la fuerza militar. El 9 de mayo, presentando el texto, el director John Chipman dijo que los Estados Unidos, además, deben promover "el mantenimiento de la paz y la construcción de estructuras estatales" (nation building) y que deben mostrar un mayor compromiso con los "Estados clave del mundo". Ejemplificó con la "relativa pasividad" de la política exterior de Bush respecto del Medio Oriente y con su énfasis en la seguridad en detrimento del desarrollo, en América Latina.

\section{La solución del problema del terrorismo no supone el uso exclusivo de la fuerza militar.}

\section{LA NUEVA DOCTRINA}

Los asesores presidenciales menos militaristas, entre los cuales está el Secretario de Estado Colin Powell -quien no por nada es un militar distinguido-, aprovecharon los síntomas de malestar en el campo propio para sacar la voz. Quizás por eso, el 14 de marzo Bush anunció, desde el BID, su primer programa de apoyo al desarrollo de los países más pobres, con un presupuesto de 5 mil millones de dólares. Es la octava parte del incremento de su gasto militar, pero le permitió, pocos días después, un ejercicio de sociabilidad civil en la Cumbre de Monterrey.

Sin embargo, como se ha visto, su tendencia a las soluciones militares se ha mantenido y potenciado. De acuerdo con la dinámica de la fuga hacia adelante, la amenaza terrorista personalizado en Bin Laden ya se ha desplazado, casi de manera total, hacia la amenaza ultraterrorista del régimen irakí, personalizada en Hussein.

Con la mayor energía, Bush ha determinado que la vigencia de ese dictador es incompatible con la seguridad nacional de los Estados Unidos y con la paz internacional. Incluso se ha mostrado dispuesto 
a iniciar una guerra preventiva, poniendo en duros aprietos a las Naciones Unidas, pues sus ultimatum a Hussein, marginales al sistema de seguridad colectiva, deben entenderse como extensibles al Consejo de Seguridad de la organización mun$\operatorname{dial}^{6}$.

\section{En su documento al Congreso, Bush declara tácitamente obsoleta la contención mediante la disuasión estratégica.}

Para consolidar ese desplazamiento, el líder norteamericano lo ha "doctrinarizado". Al efecto, el 20 de septiembre envió al Congreso un documento de 33 páginas titulado "La estrategia de seguridad nacional de los Estados Unidos". En éste, a partir de la premisa de que se requieren "acciones anticipadas para defendernos, aun si quedan incertidumbres sobre el momento y el lugar del ataque enemigo", declara tácitamente obsoleta la contención mediante la disuasión estratégica. Concordante con ello, pasa desde la tesis de "no proliferación" de armas de destrucción masiva a la de "contra-proliferación" y subordina los acuerdos y tratados internacionales a la decisión unilateral de la superpotencia, cuando se perciba la amenaza de otros Estados u organizaciones. A este respecto advierte que, sin perjuicio de que los Estados Unidos pidan el apoyo de la comunidad internacional, deben "actuar so- los, si hay que hacerlo, para ejercer nuestro derecho de autodefensa, actuando de manera preventiva contra la amenaza terrorista".

Sugerentemente, esta "Doctrina Bush", antítesis de las históricas "Doctrina Wilson" y "Doctrina Truman", se presentó a menos de dos meses de las elecciones parlamentarias del 5 de noviembre. De esta manera, el gobierno levantó ante su oposición demócrata una política de interés global, como un test patriótico con expresión electoral. Su intención sería colocarla entre la espada de sus convicciones estratégicas más flexibles y la pared de la hegemonía republicana en el Congreso.

Al cierre de este artículo, para contrarrestar la maniobra, el Partido Demócrata estaba recurriendo a sus líderes y personalidades más conocidos. En el marco de una conferencia universitaria, el senador Ted Kennedy advirtió que el gobierno no ha sustentado adecuadamente la necesidad de una guerra preventiva contra Irak: "La guerra debe ser el último recurso y no la primera respuesta".

En una entrevista por televisión, el ex presidente Bill Clinton reconoció la amenaza de las armas de destrucción masiva de Irak, pero advirtió que los Estados Unidos deben pasar "a través de las Naciones Unidas y no actuar solos".

Madeleine Albright, la Secretaria de Estado de Clinton, reapareció formulando una dura observación en The New York

${ }^{6}$ Véase artículo del autor “¿Funeral para la ONU?”, en La Nación, 5-10-02. 
Times: "No le hemos proporcionado al gobierno de Hamid Karzai ni siquiera una fracción de la ayuda que necesita para convertir a su nación en una zona libre de terrorismo". Sobre esa base, llamó a perseverar en "el foco correcto", pues "no podemos pelear una nueva lucha monumental sin antes terminar con la primera". Sin desconocer que Hussein es un peligro para la paz, hizo un llamado a la coherencia: "más que Irak, nuestra meta principal debe ser la total destrucción y desorganización de Al Qaeda y de las redes terroristas relacionadas con ese grupo"7.

El ex vicepresidente $\mathrm{Al}$ Gore ha sido el más contundente. En conferencia en el club Commonwealth, de San Francisco, dijo que el afán de Bush por iniciar una guerra contra Irak dañaría "para siempre" el rol global de los Estados Unidos y revertiría la corriente solidaria pos 11-S: "Hemos desperdiciado este apoyo y en un año lo hemos reemplazado por el miedo, la ansiedad y la incertidumbre, no sobre lo que los terroristas van a hacer, sino sobre lo que nosotros vamos a hacer".

\section{Una guerra contra Irak dañaría para siempre el rol global de los Estados Unidos.}

De manera simultánea, los analistas de la prensa volvieron a levantar las experiencias y las motivaciones ocultas de las políticas de fuerza. Stanley J. Kutler apuntó, desde Los Angeles Times, que "Bush debería recordar las lecciones claras, dolorosas, de la Guerra de Vietnam, sobre los límites de nuestro poder y fuerza para imponer nuestra voluntad sobre otros, los riesgos del unilateralismo y la falta de apoyo en la comunidad internacional". Agregó que "debería recordar la determinación de su padre para construir una gran coalición internacional en la Guerra del Golfo". Bob Dean, de The New York Times, ya comenzó a acusarlo por un diversionismo similar al que se imputó a Clinton, cuando estalló el caso Lewinsky: "Bush ha fijado su atención en Bagdad precisamente en una época de declinante crecimiento económico, crecientes déficit presupuestarios, éxitos poco consistentes en la guerra contra el terrorismo y crecientes preguntas acerca de los posibles vínculos de la Casa Blanca con escándalos corporativos" $"$

\section{BALANCE QUE ALARMA}

El balance anual de la primera etapa de la guerra antiterrorista, supone la formulación de dos preguntas medulares. Una, relativa a si se ha cumplido el objetivo de restablecer el estatus de seguridad interno y, por tanto, si los Estados Unidos se perciben hoy como un país más seguro. La otra, sobre si ese objetivo pudo

\footnotetext{
${ }^{7}$ Madeleine Albright, "El real lugar de Irak en la lucha antiterrorista", reproducido por El Mercurio, 18-9-02.

${ }^{8}$ Columna reproducida en El Mercurio, 2-9-02.

${ }^{9}$ Columna reproducida en El País de Montevideo, 24-9-02.
} 
o podrá cumplirse sin detrimento de la democracia y los valores fundamentales que representan los Estados Unidos, en cuanto potencia hegemónica de la cultura occidental

\section{Cabe preguntarse si el restablecimiento de la seguridad interna puede lograrse sin detrimento de la democracia.}

Sobre la primera interrogante, está claro que los cambios fulgurantes de imagen y de estrategia del gobierno no han traído mayor seguridad a los norteamericanos. Comprensible: la ciudadanía ya sabe que si se hubieran podido cruzar los datos de inteligencia existentes antes del 11-S, plasmarlos en un documento ejecutivo y someter éste a la consideración de un liderazgo atento, la catástrofe se habría reducido o evitado. Percibe, entonces, que en el plano de la "seguridad pura" existe una especie de agujero negro, hacia el cual deriva la información más estratégica, impidiendo su adecuado procesamiento y su conversión en planes operativos.

En el intertanto, siguen las noticias sobre aviones comerciales en peligro, lo cual ha hecho que su uso sea cada vez más restringido. La amenaza del antrax ya provocó una psicosis y la cruel ejecución del periodista David Pearl machacó sobre el trauma. La prensa informa que la red de Al Qaeda comprende 68 países y que en los Estados Unidos mantiene un centenar de topos. El 8 de mayo el sector público estuvo atento a la operación "patio nublado" (Misty Courtyard), simulacro de ataque con armas químicas o biológicas. El 19 de mayo, el vicepresidente Dick Cheney dijo, desde un programa de televisión, que había que mantener alta la guardia porque la realización de ataques terroristas de gran magnitud contra los Estados Unidos "es prácticamente una certeza". Ese mismo día, el FBI alertó sobre la posibilidad de que los terroristas estuvieran almacenando explosivos en departamentos de edificios residenciales, para provocar diversas hecatombes simultáneas.

Como paradigma del complejo de inseguridades, ya existe una Casa Blanca de reemplazo, escondida en bunkers secretos, por si desapareciera el gobierno oficial de Washington. Esto confirma que la posibilidad de la peor hipótesis -el terrorismo nuclear- luce probable.

Asumiendo el estado de miedo imperante, la Brookings Institution, centro de estudios liberal con sede en Washington, publicó a comienzos de mayo un informe titulado "Protegiendo la nación americana". Su objetivo: analizar los efectos eventuales de un nuevo ataque terrorista masivo y evaluar la consistencia y coherencia de las medidas antiterroristas en desarrollo o planificación. Tras cálculos pavorosos sobre mortandades por agentes diversos, llegó a la siguiente conclusión: "El gobierno de Bush ha creado una amplia gama de nuevos programas para enfrentar el tema del terrorismo; sin embargo, esto no es sufi- 
ciente, ya que no se ha logrado producir un plan estratégico global para proteger a la nación".

Al margen de que el presidente creyó solucionar la carencia formal anotada con su texto doctrinario del 20 de septiembre, lo señalado supone un serio cuestionamiento a su trabajo. Y así pareció corroborarlo una encuesta publicada el 20 de mayo por The Washington Post, según la cual un 46 por ciento de los encuestados cree que el gobierno pudo hacer más para evitar los atentados de septiembre. Dicha encuesta mostró, además, un descenso del 55 al 46 por ciento del número de estadounidenses que confía en la capacidad del gobierno para prevenir nuevos ataques.

Adelantándose a estos impactos en la línea de flotación política, el Fiscal General John Ashcroft ya había instado a los vecinos a patrullar sus barrios para detectar posibles terroristas. Luego, a fines de mayo, autorizó al FBI para espiar grupos, organizaciones o individuos, haya o no sospecha razonable de actividades terroristas. También reintrodujo a la CIA en las tareas de espionaje interno aunque, para no chocar con la legislación prohibitiva a ese respecto, lo presentó como una especie de asesoría técnica al FBI.

\section{EL RIESGO DE NO SER}

El vicepresidente Cheney, en el citado programa de televisión, invitó a la ciudadanía a una vigilancia constante. Sin embargo, introdujo un importante y revelador matiz, al agregar que eso no debía cambiar las pautas de vida de la nación. "Si no fuera así, sería una victoria de los terroristas", señaló.

\section{Los Estados Unidos confrontan un problema de identidad con proyección global.}

En ese matiz está el meollo de la segunda pregunta del balance. La de si los Estados Unidos, mediante la Doctrina Bush, pueden vencer al terrorismo, recuperar sus pautas históricas de seguridad interna y seguir siendo una democracia modélica de Occidente.

Se trata, en esencia, de un problema de identidad con proyección global. Porque, si para mantener a raya a los terroristas y derrocar a Hussein se van a afectar las bases culturales de la nación -con su democracia desarrollada, el poder político disperso, las garantías efectivas contra la violación de los derechos fundamentales y su ética solidarista o compasiva- estaríamos hablando de unos Estados Unidos diferentes.

Cabe advertir que otras coyunturas dramáticas, en conflictos de larga data, han inducido a abandonar o rechazar los valores culturales de Occidente, para refugiarse en el bunker de los mitos. Como ejemplos actuales tenemos al líder israelí Ariel Sharon, quien sólo cree en los métodos militares para poner fin al conflicto del Medio Oriente y al líder palestino Yasser Arafat, quien usa un doble lenguaje para disimular sus pretensiones escatológicas -la desaparición de Israel-y/o porque ca- 
rece de una estrategia política de fin de conflicto $^{10}$.

En los Estados Unidos, aquella fuga de los valores de Occidente equivaldría a un presidente Bush que quería ser Reagan, pero tiene que convertirse en Superman para soslayar la complejidad real del fenómeno terrorista. Digamos, como digresión, que el superhéroe de historieta nació en 1938 y, según sus exégetas, vino para enfrentar a los superhombres de la mitología nazifascista ${ }^{11}$.

El problema es inquietante, pues en los primeros años de la Guerra Fría se dio el esbozo de un precedente. Fue cuando, macartismo mediante, algunos norteamericanos creyeron que la contención del comunismo obligaba a transformar su sociedad democrática en una sociedad policial y a cultivar amistades sospechosas. En definitiva, aquello fortaleció a todos los dictadores anticomunistas del mundo y dio origen a la posterior distinción -de errónea base- entre las redimibles dictaduras autoritarias y las inmutables dictaduras totalitarias.

El macartismo originó la distinción entre las redimibles dictaduras autoritarias y las inmutables dictaduras totalitarias.
La advertencia de Cheney afectaría, entonces, el rol global de los Estados Unidos. En los países árabes, por ejemplo, ya se están percibiendo los efectos antioccidentales de la estrategia de Bush, en cuanto desincentivación de la idea democrática. Mahmoud ben Romdhane, académico y ex directivo de Amnesty International, ha advertido que "para los demócratas del mundo árabe-musulmán, el escenario posterior al 11 de septiembre del 2001 representa una regresión espectacular del estado de las libertades y marca un fortalecimiento de las tendencias totalitarias que están obrando en sus propios países" ${ }^{12}$.

Como importante efecto colateral, esa mutación eventual de los Estados Unidos, con su proyección antidemocrática, podría inducir un traspaso de patrimonio cultural a la Unión Europea. Dejaría a los países comunitarios como los encargados de mantener la herencia de las libertades democráticas implícita en el concepto de Occidente.

Curiosísimamente, algo de esto está visualizando Francis Fukuyama, uno de los teóricos top del gobierno. En un artículo reciente, el autor de El fin de la Historia juega con la hipótesis de que, tras el discurso sobre "el eje del mal", la civilización occidental se estaría bifurcando. Textualmente: "Un enorme espacio se abrió entre las percepciones norteameri-

${ }^{10}$ Véase artículo del autor "Conflicto israelo-palestino: estado de situación”, en revista Estudios Internacionales, $\mathrm{N}^{\circ} 136$, octubre-diciembre 2001.

${ }^{11}$ Jacques Marny, Le monde étonnant des bandes dessinées, París, Ed. du Centurion, 1968, pág. 122.

${ }^{12}$ Mahmoud ben Romdhane, "El punto de vista de un demócrata árabe", en revista Ideele, del Instituto de Defensa Legal, Lima, septiembre 2002. 
canas y europeas sobre el mundo, y la sensación de compartir valores se está diluyendo fuertemente". Consecuente con esa afirmación, se pregunta si el concepto de Occidente puede mantener su sentido en la primera década del siglo XXI y si la línea divisoria de la globalización no se está ubicando, ahora, entre los Estados Unidos y el resto del mundo ${ }^{13}$.

El mayor riesgo de tal hipótesis es que equilibraría la superioridad militar de los Estados Unidos con una soledad inédita, muy apta para que sus adversarios cedan a la tentación de desafíos estratégicos renovados. Fukuyama apunta así, quizás sin pretenderlo, a una paradoja que lo afecta. Porque Bush, en la huella de su tesis del fin de la Historia, podría inducir una guerra intercivilizacional de pronóstico reservado.

Como un moderno aprendiz de brujo, tras tocar la flauta de Fukuyama, terminaría ejecutando la partitura de Samuel Huntington.

\section{IMPRESIONES Y CONCLUSIONES}

En Occidente, sólo Margaret Thatcher ha aplaudido sin reservas el talante guerrero de George W. Bush. Desde su noble retiro, la ex "dama de hierro" lo ve como un replicante de Ronald Reagan y percibe al terrorismo islámico como un sustituto del bolchevismo soviético.

Pero, para la mayoría de los analistas y observadores, el líder norteamericano es un presidente más autoritario que li- bertario y más populista que pragmático. Se le encasilla a una distancia sideral del bondadoso Jimmy Carter y lejos de los presidentes intelectuales como Woodrow Wilson, Franklin D. Roosevelt y John F. Kennedy. Lejos, también, de los presidentes informados como su padre. Hasta el momento, parece más cercano a los líderes "simples pero resueltos", como Harry Truman y estaría a corta distancia de Richard Nixon, pero no por su manejo de la política exterior, precisamente.

\section{Si la línea divisoria de la globalización estuviera entre Estados Unidos y el resto del mundo, se equilibraría su superioridad militar con una soledad inédita.}

A partir de esa filiación de liderazgo, vayan las siguientes cuatro conclusiones tentativas sobre su novísima Doctrina:

Primera: la Doctrina Bush comenzó a afectar la teoría tradicional de la guerra y hasta los futuribles sobre el orden mundial del siglo XXI.

Segunda: su componente unilateralista es funcional para mantener y/o incrementar los sentimientos adversos hacia la superpotencia, que generan el terrorismo.

Tercera: por la naturaleza del enemigo, no podrá verificarse mediante un éxito dirimente, como sucediera con la doctrina de la contención con disuasión, a finales del siglo XX.

\footnotetext{
${ }^{13}$ Francis Fukuyama, “Occidente se está fracturando”, artículo reproducido por La Tercera, 8-9-02.
} 
Cuarta: es de tal ambivalencia prospectiva, que a partir de Fukuyama puede conducir a Huntington, con un fortalecimiento de los regímenes antidemocráticos y una eventual guerra intercivilizacional.
Esta cuarta conclusión demostraría, de paso, que el valor práctico de las tesis creativas depende, fundamentalmente, de la audacia de los asesores que las promueven y de los líderes que las aplican. 